\title{
Neonatal Exposure to 6-n-Propyl-Thiouracil, an Anti-Thyroid Drug, Alters Expression of Hepatic DNA Methyltransferases, Methyl CpG-Binding Proteins, Gadd45a, p53, and PCNA in Adult Male Rats
}

\author{
Suresh Kumar Bunker Jagneshwar Dandapat Gagan B.N. Chainy \\ Sunil Kumar Sahoo Prabhat Kumar Nayak \\ Department of Biotechnology, Utkal University, Bhubaneswar, India
}

\section{Keywords}

Neonatal hypothyroidism · 6-n-Propyl-2-thiouracil · DNA methyltransferases - Methyl-DNA binding proteins .

Gadd45a · p53 · Proliferating cell nuclear antigen - Liver · Rat

\begin{abstract}
Background: Neonatal 6-n-propyl-2-thiouracil (PTU) exposure to male rats is reported to impair liver function in adulthood. However, the mechanism by which the drug impairs liver function is not well known. Objectives: The objectives of the study were to investigate the effects of neonatal exposure of PTU on the expression of DNA methyltransferases (DNMTs), methyl-DNA binding proteins (MBDs), Gadd45a, p53, and proliferating cell nuclear antigen (PCNA) in adult rat liver. Methods: The effects of neonatal transient (from birth to 30 days of age) and persistent (from birth to 90 days of age) treatment of PTU on DNA damage and on the expression of p53, PCNA, DNMTs, and MBDs were investigated at transcriptional and translational levels in male adult liver. Results: Persistent exposure to PTU from birth caused significant downregulation of expression of DNMT1 and DNMT3a and upregulation of DNMT3b, MBD4, and Gadd45a
\end{abstract}

without any damage to DNA. Although MeCp2 transcripts were significantly low in the liver of adult rats after persistent exposure to PTU compared to controls, its translated products were significantly higher than in controls. The expression of p53 and PCNA in PTU-treated rats was significantly higher and lower, respectively, than that in control rats. Conclusion: The results suggest that neonatal exposure of male rats to PTU resulted in alteration in the expression of proteins that are associated with DNA methylation and genome stabilization in adult rat liver.

(c) 2017 European Thyroid Association Published by S. Karger AG, Basel

\section{Introduction}

Clinical use of 6-n-propyl-2-thiouracil (PTU), an antithyroid drug, in general and particularly in children is a matter of concern $[1,2]$. It has been reported that the interruption of actions of thyroid hormones by anti-thyroid drugs such as methimazole or PTU during the foetal and neonatal period of vertebrates results in impairment of hepatic gene expression in adulthood $[3,4]$.

\section{KARGER}

E-Mail karger@karger.com

www.karger.com/etj (c) 2017 European Thyroid Association

Published by S. Karger AG, Basel
Gagan B.N. Chainy

Department of Biotechnology, Utkal University

Bhubaneswar

Odisha 751004 (India)

E-Mail chainyg@gmail.com 
Table 1. Accession numbers, gene-specific primer sequences, annealing temperature, and product size of G3PDH, DNMT1, DNMT3a, DNMT3b, MBD4, MeCP2, Gadd45a, p53, and PCNA

\begin{tabular}{|c|c|c|c|c|}
\hline Primers & Accession No. & Primer sequences $\left(5^{\prime}-3^{\prime}\right)$ & $\begin{array}{l}\text { Annealing } \\
\text { temperature, } \\
{ }^{\circ} \mathrm{C}\end{array}$ & $\begin{array}{l}\text { Product } \\
\text { size, } \\
\text { bp }\end{array}$ \\
\hline G3PDH & NM_017008.4 & $\begin{array}{l}\text { S-ATGGAGAAGGCTGGGGCTCACCT } \\
\text { AS-AGCCCTTCCACGATGCCAAAGTTGT }\end{array}$ & 60 & 209 \\
\hline DNMT1 & NM_053354.3 & $\begin{array}{l}\text { S-ACCTACCACGCCGACAT } \\
\text { AS-AGGTCCTCTCCGTACTCCA }\end{array}$ & 60 & 104 \\
\hline DNMT3a & NM_001003957.2 & $\begin{array}{l}\text { S-CAGCAAAGTGAGGACCATTA } \\
\text { AS-AACACCCTTTCCATTTCAG }\end{array}$ & 60 & 123 \\
\hline DNMT3b & NM_001003959.1 & $\begin{array}{l}\text { S-GAATTTGAGCAGCCCAGGTTG } \\
\text { AS-AAGAAGAGCCTTCCTGTGCC }\end{array}$ & 60 & 310 \\
\hline MBD4 & XM_002726448.3 & $\begin{array}{l}\text { S-CCTACCGGATCTTTTGTGTCA } \\
\text { AS-GATTTTCCCAAAGCCAGTCAT }\end{array}$ & 60 & 120 \\
\hline $\mathrm{MeCP} 2$ & NM_022673.2 & $\begin{array}{l}\text { S-ACTTCTCGTCAAGATGCCTTTCC } \\
\text { AS-TTTTCGCTTTCTGCCAAGGG }\end{array}$ & 60 & 112 \\
\hline Gadd45a & NM_024127.2 & $\begin{array}{l}\text { S-ATTCGTGCTTTCTGTTGC } \\
\text { AS-GCTCTTGTCGTTCTCCAGTA }\end{array}$ & 60 & 96 \\
\hline p53 & NM_030989.3 & $\begin{array}{l}\text { S-CTACTAAGGTCGTGAGACGCTGCC } \\
\text { AS-TCAGCATACAGGTTTCCTTCCACC }\end{array}$ & 60 & 106 \\
\hline PCNA & NM_022381.3 & $\begin{array}{l}\text { S-TAAGGGCTGAAGATAATGCTGAT } \\
\text { AS-CCTGTTCTGGGATTCCAAGTT }\end{array}$ & 60 & 126 \\
\hline
\end{tabular}

DNA methylation, an epigenetic phenomenon, has been recognized as an interface between genome and the environment; therefore, epigenetic deregulation is likely to be involved in the aetiology of human diseases associated with environmental exposure [5]. Two families of proteins have significant roles in DNA methylation and gene expression in mammals. They are the families of DNA methyltransferases (DNMT1, DNMT2, DNMT3a, and DNAMT3b) and methyl CpG-binding proteins (MBD1, MBD2, MBD3, MBD4, and MeCP2). DNMT3a and DNMT3b are mostly involved in de novo methylation of cytosine residues, whereas DNMT1 maintains the DNA methylation pattern upon chromosome replication while the functions of DNMT2 are not fully established [6]. MBD1, MBD2, MBD3, and MeCP2 are responsible for methylation-dependent repression of genes by binding to methylated CpG sites [7]. MBD4 is considered to act as thymine DNA glycosylase, repairing G:T or G:U mismatches in CpG sites [8], and as a transcription repressor [9]. Gadd45a gene, a member of the stress response gene family, is involved in genomic stability, DNA repair, cell cycle checkpoints, and suppression of cell growth [10].
Similarly, p53 protein is known to maintain genome stability in response to diverse stress signals by coordinating specific cellular responses that include cellular activities in cell cycle, DNA repair, and apoptosis [11].

Our knowledge on PTU-induced changes in the status of proteins associated with DNA methylation and genome stabilization in rat liver during development is very poor. This has prompted us to determine the status of expression of some important proteins associated with DNA methylation (DNMT1, DNMT3a, DNMT3b, MBD4, and MeCP2), genome stabilization (Gadd45a and p53), and cell proliferation (proliferating cell nuclear antigen, PCNA) in the liver of adult male rats in response to neonatal PTU treatment in order to understand the mechanism of its hepatotoxicity.

\section{Materials and Methods}

Chemicals and Animals

Chemicals, biochemicals, molecular biology reagents, kits used in the present study, animal maintenance, care, Western blotting, and qPCR have been mentioned earlier in detail [4]. Rabbit poly- 


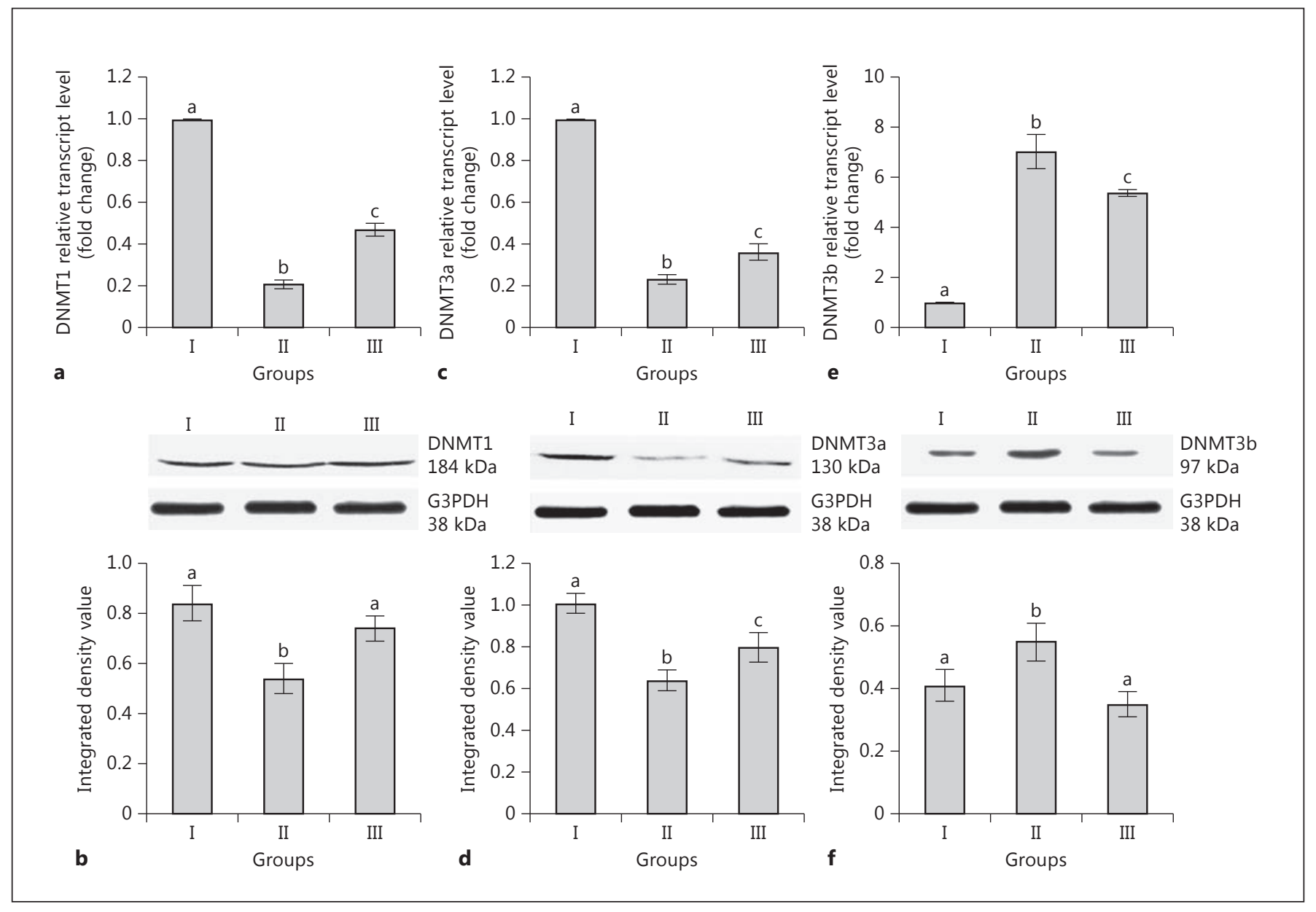

Fig. 1. Effects of neonatal 6-n-propyl-2-thiouracil (PTU) treatment on transcript and translated protein levels of $\operatorname{DNMT1}(\mathbf{a}, \mathbf{b}), \operatorname{DNMT3a}(\mathbf{c}, \mathbf{d})$, and DNMT3b $(\mathbf{e}, \mathbf{f})$ in adult rat liver. Group I: control rats (90 days old); group II: rats were treated with PTU for 90 days after birth; group III: rats were treated with PTU for 30 days after birth and thereafter the treatment was withdrawn for 60 days. Data are expressed as the mean \pm SD of 5 animals. Bars with different superscript letters differ significantly $(p<0.05)$ from each other.

clonal anti-glyceraldehyde-3 phosphate dehydrogenase (G3PDH), DNMT1, DNMT3a, DNMT3b, MBD4, MeCP2, Gadd45a, p53, PCNA, biotin goat anti-rabbit IgG, and horseradish peroxidase (HRP)-conjugated anti-rabbit goat IgG were purchased from Santa Cruz Biotechnology, Inc. (Santa Cruz, CA, USA), whereas streptavidin-HRP conjugate was purchased from Genei, India. Animal care, maintenance, and experiments were performed under the supervision of the Institutional Animal Ethics Committee (IAEC) regulated by the Committee for the Purpose of Control and Supervision of Experiments on Animals (CPCSEA), Government of India.

\section{Experimental Design}

In brief, as soon as the pups were born, dams (6-month-old female rats, weighing about $225-250 \mathrm{~g}$ ) were divided into 2 groups: control mother rats given drinking water and hypothyroid mother rats given $0.05 \%$ PTU in drinking water. Hypothyroidism was induced in male neonates by feeding the lactating mothers with
0.05\% PTU through the drinking water from the day of parturition until weaning (25 days postpartum), and then directly through drinking water containing $0.05 \%$ PTU for the remaining period of experimentation. All pups used in this experiment were male Wistar rats (Rattus norvegicus). The animals were divided into 3 groups each containing 5 male animals.

Group I: control rats (90 days old).

Group II: rats were treated with PTU for 90 days after birth.

Group III: rats were treated with PTU for 30 days after birth and thereafter the treatment was withdrawn for 60 days. Control and experimental animals were sacrificed on the 91st day of birth.

\section{Tissue Preparation, Western Blotting, RNA Isolation, and cDNA Preparation}

Tissue preparation, total RNA isolation, cDNA synthesis, and real-time PCR analysis with gene-specific primer using SYBR Green PCR master mix have been described earlier [4]. The primer sequences are presented in Table 1. All results were normalized 


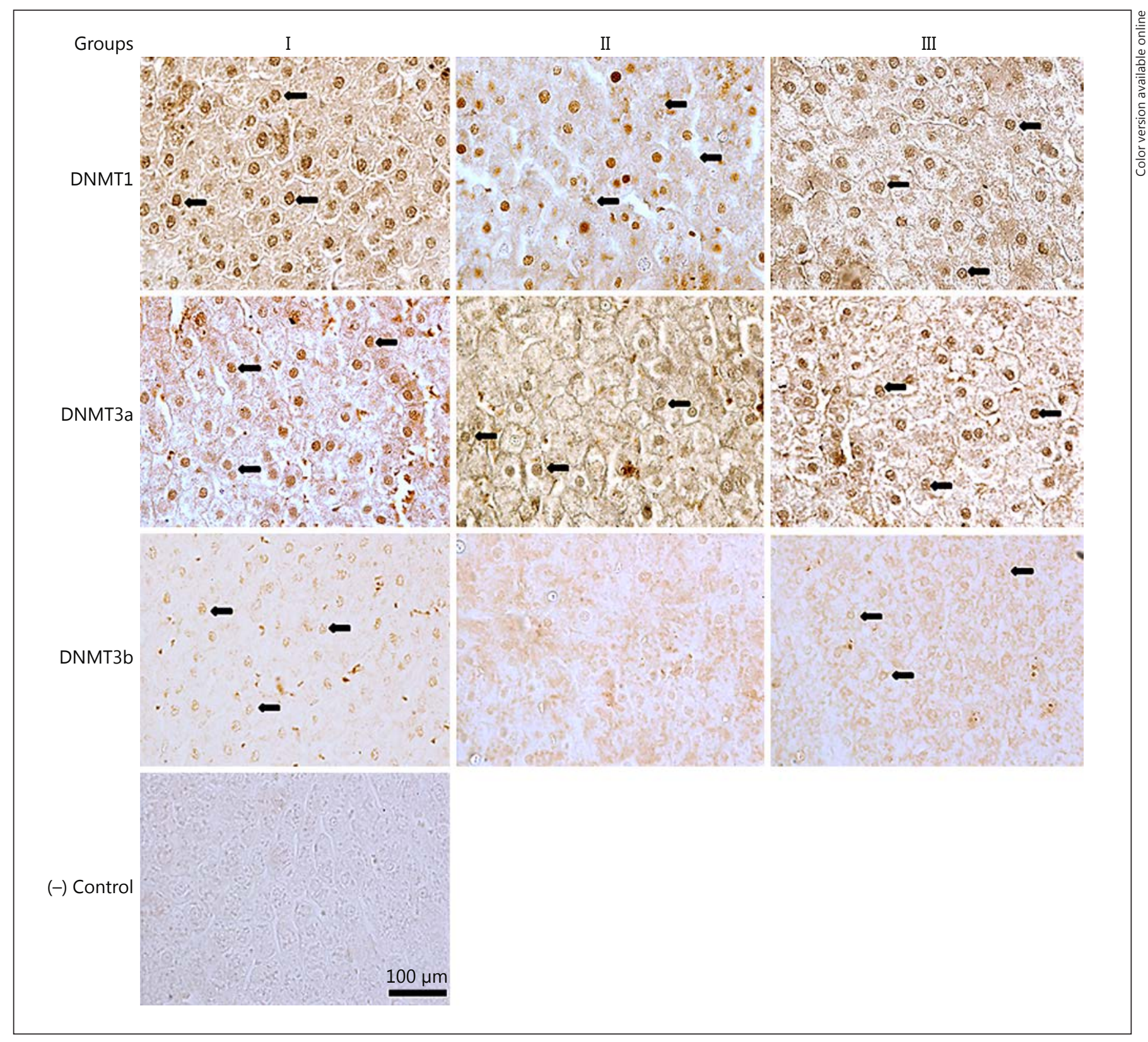

Fig. 2. Representative photomicrographs of transverse sections of liver showing positive nuclear immunostaining for DNMT1, DNMT3a, and DNMT3b, and negative (-) control. All sections were counterstained with $1 \%$ methyl green except DNMT3b. See legend to Figure 1 for an explanation of the groups. Magnification, $\times 400$. Scale bar, $100 \mu \mathrm{m}$.

with the G3PDH gene (endogenous control). PCR was repeated in 3 replicates for each sample. The expression levels were calculated by the $\Delta \Delta$ CT method [12].

Western blotting of liver homogenates $(20-25 \mu \mathrm{g})$ was performed by incubating the PVDF membrane with rabbit polyclonal anti-G3PDH (1:1,000), anti-DNMT1 (1:500), anti-DNMT3a (1:500), anti-DNMT3b (1:500), anti-MBD4 (1:500), anti-MeCP2 (1:500), and Gadd45a (1:500) followed by HRP-conjugated anti- rabbit goat IgG (G3PDH - 1:7,500, and DNMT1, DNMT3a, DNMT3b, MBD4, MeCP2, and Gadd45a - 1:5,000) and expressed as previously described [4].

DNA Fragmentation Assay and Detection of DNA Damage by Alkaline Comet Assay

The DNA fragmentation assay and DNA alkaline comet assay were carried out according to the methods of Perandones et al. [13] 
and Singh et al. [14], respectively. Protein content in samples was measured according to Bradford [15].

\section{Immunohistochemistry}

Liver sections were incubated with rabbit polyclonal primary antibodies against DNMT1 (1:30), DNMT3a (1:25), DNMT3b (1:25), MBD4 (1:25), MeCP2 (1:25), Gadd45a (1:25), PCNA (1:25), and p53 (1:50) followed by washing, incubating with biotinylated goat anti-rabbit IgG (1:200) and streptavidin-HRP conjugate (1:200), and visualized by incubating with $0.5 \%(\mathrm{w} / \mathrm{v}) 3,3$-diaminobenzidine (DAB) followed by methyl green counter staining [4].

\section{Labelling Index}

Three different sections per animal and 3 animals per experimental group were chosen for positive nuclear immunoreaction counting. Hepatocytes with a distinct nucleus and cell boundary were considered for counting. Counting was done by Q-Capture pro7 image analysis software, and the percentage of positive nuclear immunostaining $/ \mathrm{mm}^{2}$ was quantified.

\section{Statistical Analyses}

Data were presented as mean $\pm \mathrm{SD}(n=5)$ and were analysed by one-way analysis of variance (ANOVA) followed by the Tukey test to determine the level of significance among the mean values. Band intensities of Western blots and PCR products were quantified using computer-assisted densitometry Image Quant TL, Image Analysis Software v2003.The minimal statistical significance was considered at $p \leq 0.05$ levels.

\section{Results}

\section{Expression of DNMT1, DNMT3a, and DNMT3b}

The expression of mRNA and protein of DNMT1 (Fig. 1a, b) and DNMT3a (Fig. 1c, d) was significantly lower in group II than group I. Although the transcripts and translated products of DNMT1 were significantly higher in group III than group II, the transcript level in group III was significantly lower than group I (Fig. 1a, b). The transcript level of DNMT3b was significantly higher in group II and III rats than in group I (Fig. 1e). Translated products of DNMT3b were significantly higher in group II rats than in group I (Fig. 1f).

Although nuclear immunostaining of DNMT1, 3a, and $3 \mathrm{~b}$ in groups I and II was positive and conspicuous (Fig. 2), immunostaining of nuclei for DNMT3b in group II was faint and inconspicuous with diffuse cytoplasmic staining. This posed difficulty in proper counting of nuclei in group III; hence, they were not counted. The percentages of positive nuclear staining were found to be 77 , 64 , and $70 \%$, respectively, for DNMT1, 3a, and $3 \mathrm{~b}$ in group I, which decreased to 62 and $38 \%$ for DNMT1 and $3 \mathrm{a}$ in group II. The values were 75,56 , and $70 \%$, respectively, for DNMT1, 3a, and $3 \mathrm{~b}$ in group III (Table 2).

Neonatal Exposure to PTU Affects

Hepatic Physiology in Adulthood
Table 2. Effect of neonatal 6-n-propyl-2-thiouracil (PTU) treatment on hepatic immunostaining scores in adult rats

\begin{tabular}{lcll}
\hline \multirow{2}{*}{ Proteins } & \multicolumn{3}{c}{$\%$ positive immunostaining score } \\
\cline { 2 - 4 } & Group I & Group II & Group III \\
\hline DNMT1 & $77 \pm 2.32^{\mathrm{a}}$ & $62 \pm 1.47^{\mathrm{b}}$ & $75 \pm 1.01^{\mathrm{a}}$ \\
DNMT3a & $64 \pm 3.45^{\mathrm{a}}$ & $38 \pm 0.30^{\mathrm{b}}$ & $56 \pm 0.23^{\mathrm{a}}$ \\
DNMT3b & $70 \pm 1.88^{\mathrm{a}}$ & not detected & $70 \pm 0.98^{\mathrm{a}}$ \\
MeCP2 & $7 \pm 2.01^{\mathrm{a}}$ & $48 \pm 4.13^{\mathrm{b}}$ & $14 \pm 1.76^{\mathrm{c}}$ \\
PCNA & $30 \pm 1.94^{\mathrm{a}}$ & $10 \pm 2.28^{\mathrm{b}}$ & $29 \pm 6.72^{\mathrm{a}}$ \\
\hline
\end{tabular}

Data are expressed as the mean \pm SD of 5 animals. Nuclear labelling indices are represented as the percentage of positive nuclear immunostaining $/ \mathrm{mm}^{2}$. Group I: control rats (90 days old); group II: rats were treated with PTU for 90 days after birth; group III: rats were treated with PTU for 30 days after birth and thereafter the treatment was withdrawn for 60 days. Data with different superscript letters in a row differ significantly $(p<0.05)$ from each other.

\section{Expression of MBD4, MeCP2, and Gadd45a}

The expression of mRNA and protein of MBD4 was significantly higher in group II and III rats than in group I (Fig. 3a, b). Although the transcript level of MeCP2 was significantly lower in groups II and III than group I (Fig. 3c), it was significantly higher in group III in comparison to group II. The level of MeCP2 translated products was significantly higher in group II than in groups I and III. However, there was no significant difference between group I and group III (Fig. 3d). Transcript and translated protein levels of Gadd45a were significantly higher in group II and III rats in comparison to group I (Fig. 3e, f).

There was no significant difference in MBD4 and Gad$\mathrm{d} 45 \mathrm{a}$ immunostaining patterns among the groups (data not shown). The percentages of positive nuclear staining for MeCP2 were 7, 48 and 14\% for groups I, II, and III, respectively (Fig. 4; Table 2).

\section{Expression of PCNA and $p 53$}

A significant increase of $\mathrm{p} 53$ expression was recorded in group II and III rats in comparison to group I (Fig. 5a, b). The expression of PCNA was significantly lower in group II rats than in groups I and III (Fig. 3c, d).

The percentages of positive nuclear staining for PCNA were 30,10 and $29 \%$ for groups I, II, and III, respectively (Fig. 4; Table 2). A punctate distribution of p53 was noticed in the cytoplasm of liver cells with elevated intensity in group III (Fig. 4). 

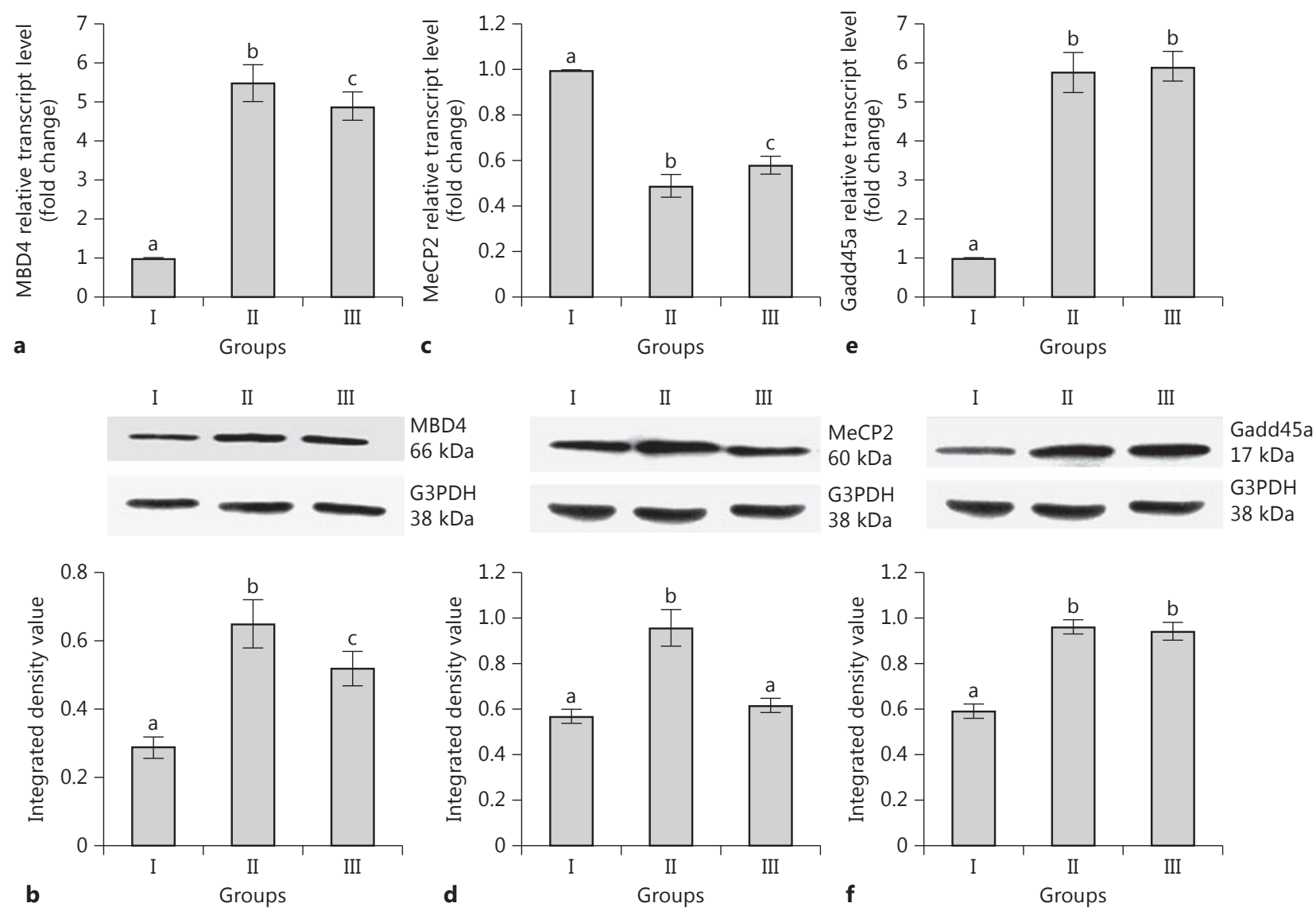

Fig. 3. Effects of neonatal PTU treatment on transcript and translated protein levels of MBD4 (a, b), MeCP2 (c, d), and Gadd45a $(\mathbf{e}, \mathbf{f})$ in adult rat liver. See legend to Figure 1 for an explanation of the groups. Data are expressed as the mean \pm SD of 5 animals. Bars with different superscript letters differ significantly $(p<0.05)$ from each other.

Table 3. Effect of neonatal 6-n-propyl-2-thiouracil (PTU) treatment on hepatic DNA fragmentation and comet assay parameters in adult rats

\begin{tabular}{lrll}
\hline Parameters & Group I & Group II & Group III \\
\hline DNA fragmentation & $2.60 \pm 0.28(100 \pm 11)$ & $2.62 \pm 0.32(100 \pm 12.30)$ & $2.50 \pm 0.30(96 \pm 11.50)$ \\
Tail length (pixel) & $3.2 \pm 0.65(100 \pm 20)$ & $3.63 \pm 0.62(113 \pm 19)$ & $3.22 \pm 0.74(101 \pm 23)$ \\
\% DNA in tail & $1.74 \pm 0.36(100 \pm 20)$ & $1.6 \pm 0.3(93 \pm 17)$ & $1.77 \pm 0.25(102 \pm 14)$ \\
Tail moment & $0.06 \pm 0.01(100 \pm 16)$ & $0.06 \pm 0.01(100 \pm 16)$ & $0.05 \pm 0.01(84 \pm 17)$ \\
\hline
\end{tabular}

Data are expressed as the mean \pm SD of 5 animals (with \% values in parentheses). Group I: control rats (90 days old); group II: rats were treated with PTU for 90 days after birth; group III: rats were treated with PTU for 30 days after birth and thereafter the treatment was withdrawn for 60 days. Data in a row do not differ significantly from each other. 


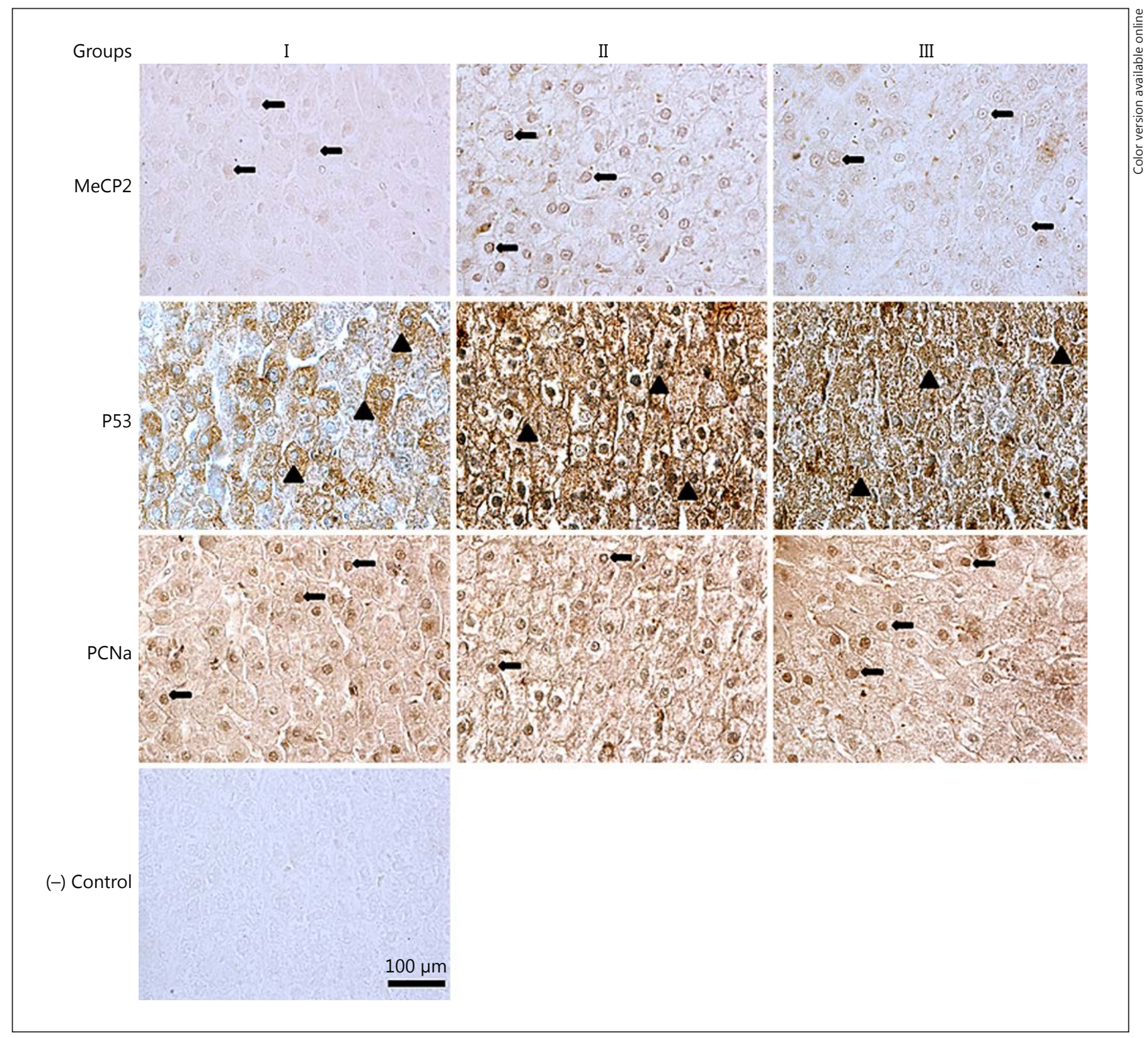

Fig. 4. Representative photomicrographs of transverse sections of liver showing positive nuclear and cytoplasmic immunostaining for MeCP2, p53, PCNA, and negative (-) control. All sections were counterstained with $1 \%$ methyl green except MeCP2. See legend to Figure 1 for an explanation of the groups. Magnification, $\times 400$. Scale bar, $100 \mu \mathrm{m}$.

\section{DNA Damage Assessment}

There was no significant difference in results of DNA fragmentation and comet assay among groups I, II, and III (Fig. 6; Table 3).

Neonatal Exposure to PTU Affects Hepatic Physiology in Adulthood

\section{Discussion}

The present study is an extension of our earlier work [4], where reduced thyroid hormones $\left(\mathrm{T}_{3}\right.$ and $\left.\mathrm{T}_{4}\right)$ with elevated TSH levels in the serum of adult male rats were recorded in response to PTU-induced neonatal hypothy- 

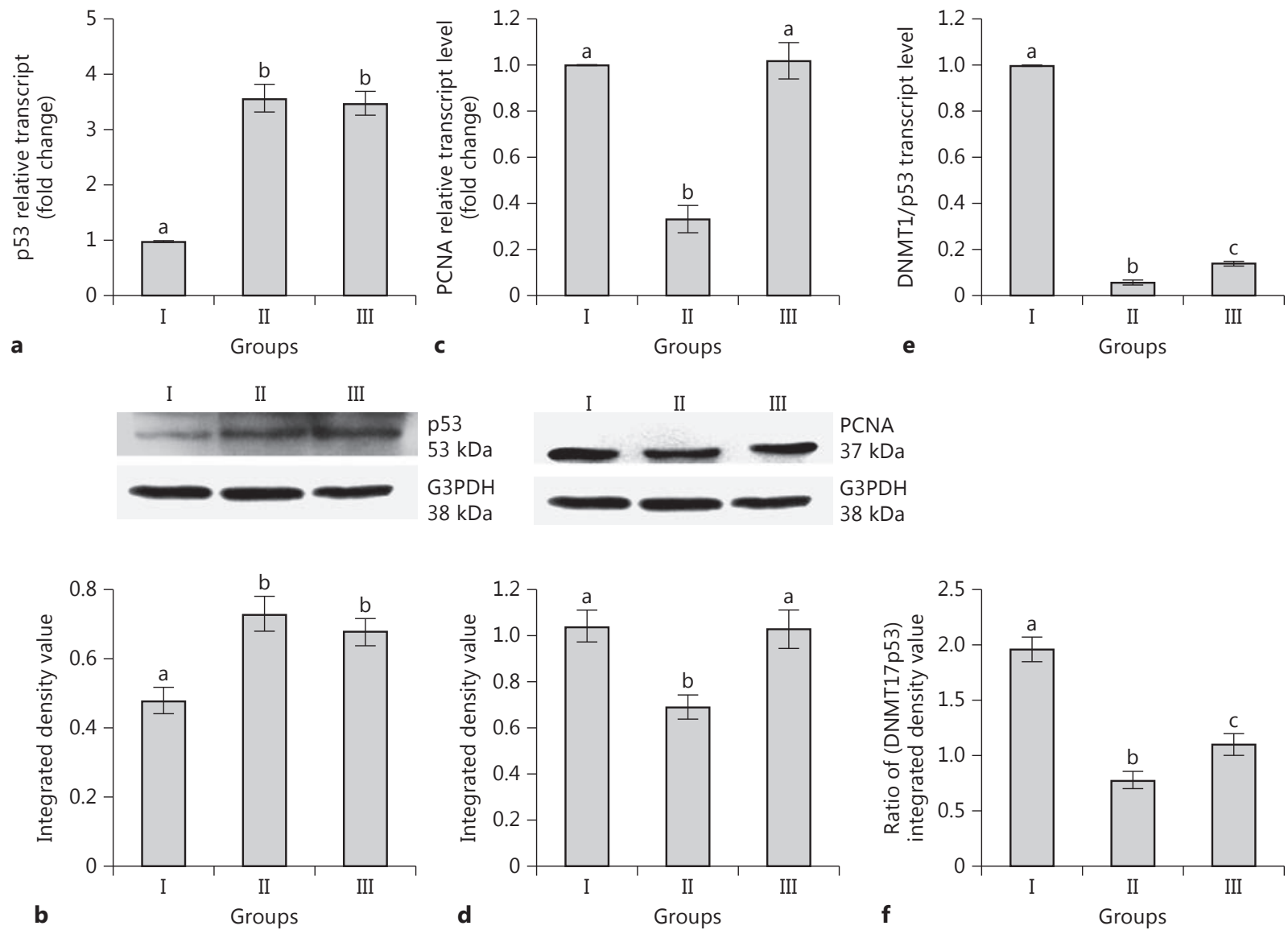

Fig. 5. Effects of neonatal PTU treatment on transcript and translated product levels of p53 (a, b) and PCNA (c, d) in adult rat liver. Representation of ratio of mRNA (e) and protein (f) expression levels of DNMT1 to p53. See legend to Figure 1 for an explanation of the groups. Data are expressed as the mean \pm SD of 5 animals. Bars with different superscript letters differ significantly $(p<0.05)$ from each other.

roidism. The hormone titres were restored to control levels on discontinuation of PTU treatment after 1 month of birth [4]. The former condition was referred to as a persistent hypothyroid state while the latter as a transient hypothyroid state. The results of the present study suggest that modulation of expression of genes associated with DNA methylation and genome stabilization in adult rat liver in response to neonatal hypothyroidism can be distinguished into 2 types: genes (DNMT1, DNMT3a, MBD4, MeCP2, and PCNA) whose expression exhibited a trend of subtle recovery on discontinuation of the drug and genes (DNMT3b and p53) whose expression was enduringly altered. Except for $\mathrm{MeCP} 2$, changes in the expression of genes by PTU are concordantly reflected by their respective protein expression. Such differential response of genes to PTU-induced hypothyroidism is difficult to explain at present and needs further work. It has been reported that thyroid hormone receptor recruitment to chromatin is linked to chromatin remodelling and commencement of gene transcription $[16,17]$. Therefore, epigenetic modifications as a result of alteration in the expression of DNMTs and MBDs due to altered thyroid hormone titres by PTU may lead to hepatic genome instability and dysfunction.

DNMT3a and DNMT3b methylate different subsets of DNA sequences in the genome, as evident by the different phenotypes of mice carrying a knockout of either methyltransferases [18]. Further, demonstration of their abil- 


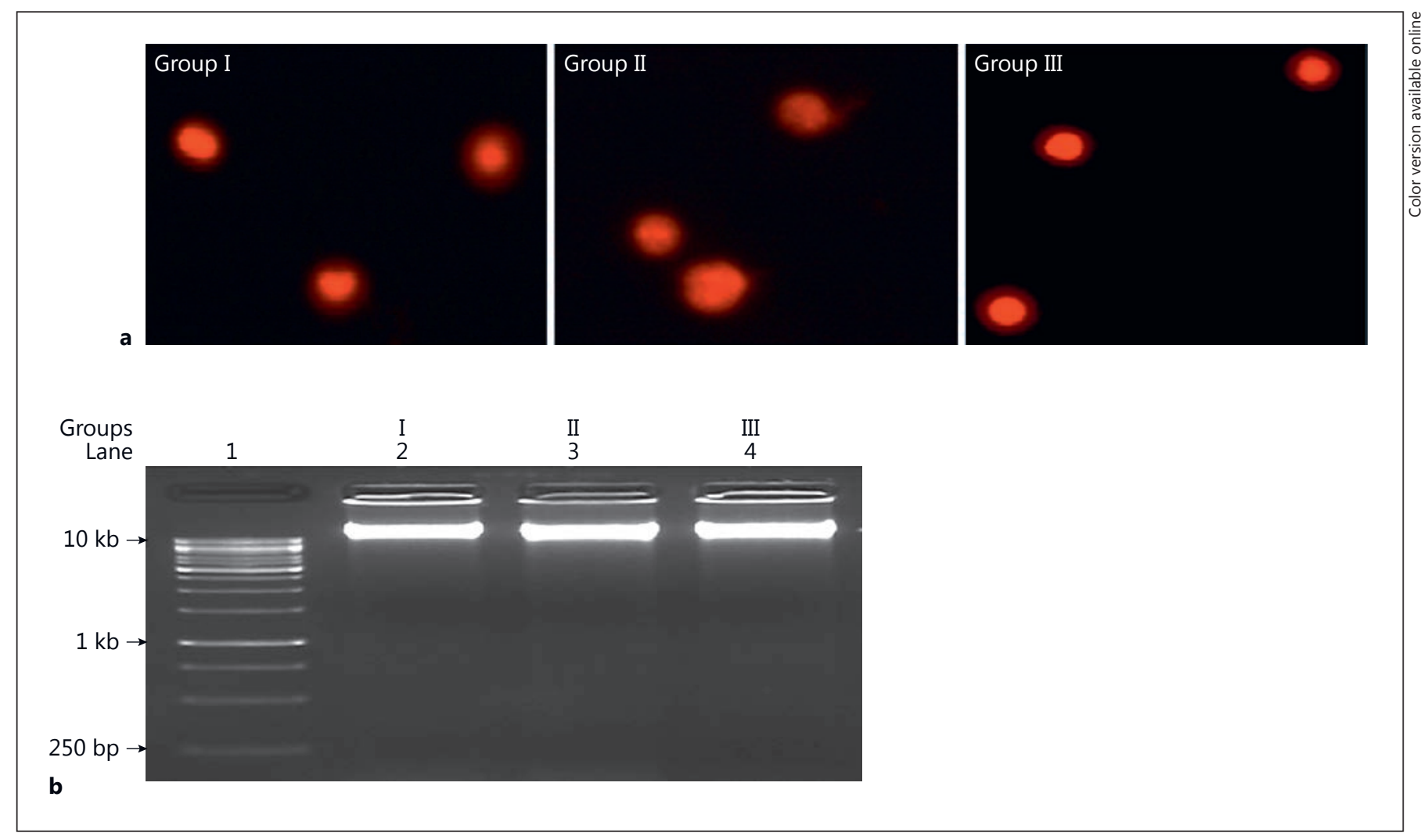

Fig. 6. Effects of neonatal PTU treatment on DNA damage. Comet assay (a) and DNA fragmentation (b) in the liver of adult male rats. See legend to Figure 1 for an explanation of the groups.

ity to convert 5-hmC to $\mathrm{C}$ directly has proposed their important role in the regulation of DNA modifications [19]. Therefore, PTU-induced reduction in the ratio of $\mathrm{DN}$ MT3a to DNMT3b may disturb dynamics of the methylation pattern of genomic DNA sequences in adulthood. Methyl CpG-binding proteins recognize methylated DNA along with associated co-repressors that lead to silencing of the genes [20]. Alterations in the expression of DNMTs and MBDs by PTU suggest that the drug may affect the expression of various genes both by preventing the binding of transcriptional factors to DNA and/or by altering the binding of MBDs through inactivation of histone deacetylase. It has been noticed that neonatal PTU treatment to rats has resulted in reduced hepatic expression of catalase and C/EBP- $\beta$ along with alteration in the methylation pattern of the catalase promoter in adulthood [4]. An upregulation of rat hippocampal DNA methyltransferase along with a downregulation of histone acetylase and global acetylated histone $\mathrm{H} 3$ and $\mathrm{H} 4$ were recorded in response to neonatal PTU treatment [21].

Neonatal Exposure to PTU Affects Hepatic Physiology in Adulthood
It is not clear from the present study whether alterations in the expression of hepatic DNMTs and MBDs are the cause or consequence of PTU-induced oxidative stress [4]. It has been reported that oxidative DNA damage produces $\mathrm{C} \rightarrow \mathrm{T}$ transition and $\mathrm{CG} \rightarrow \mathrm{TT}$ tandem mutation at methylated $\mathrm{CpG}$ sequences $[22,23]$. MBD4 has a glycosylase domain and repairs damaged DNA by removing thymine from DNA [8]. Therefore, upregulation of MBD4 by PTU may be an adaptation to counter $\mathrm{C} \rightarrow \mathrm{T}$ transition and probably facilitates the elimination of CpG:TpG mismatch [8].

MeCP2 exhibits an array of diverse functions that spans from transcriptional repression/activation, RNA splicing, to chromatin remodelling [24]. It is difficult to explain the physiological significance of an elevated MeCP2-positive hepatic cell population despite a decrease in the total number of hepatocytes by PTU [4]. The elevation of $\mathrm{MeCP} 2$ protein by PTU compared to its transcripts suggests a disturbance in regulatory key points of its translation. The increase in hepatic MeCP2 protein along with a decrease in DNMT1 protein may 
affect the genome-wide and/or specific local DNA methylation pattern [25]. It has been reported that PTU-induced hypothyroidism caused impairment of lipid metabolism in pregnant rats [26], which might be due to a change in MeCP2 expression. A recent study has shown that $\mathrm{MeCP} 2$ has a regulatory role in mouse hepatic lipid metabolism [27]. A significant decrease in hepatic $\mathrm{MeCP} 2$ transcripts despite its elevated translated products along with elevated MBD4 (both transcripts and translated products) by PTU strongly suggests that the functions of both the proteins are not gratuitous [28]. It is to mention here that functions of $\mathrm{MeCP} 2$ other than nervous system and cancer are least explored. In this report, we demonstrated changes in liver MeCP2 by PTU, an anti-thyroid agent, whose significance is yet to be established.

Under a normal physiological state there exists equilibrium among p53, Gadd45a, and PCNA in cells. The p53 regulates the induction of Gadd45a, a nuclear protein that binds to multiple important cellular proteins such as PCNA, p21, and core histone proteins [29]. Overexpression of p53 by PTU may be an adaptation to prevent replication of damaged DNA. p53 is known to arrest cell cycle, preventing replication of damaged DNA by downregulating the expression of DNMTs [30]. Products of several genes that are associated with various p53dependent cellular functions, including cell cycle arrest, are directly regulated by p53 [31]. Induction of Gadd45a has been detected in several mammalian cells in response to DNA damaging agents $[32,33]$. It has been suggested that overexpression of Gadd45a in the liver of adult rats in response to PTU may be an adaptive response to prevent DNA damage. The decrease in PCNA expression by PTU indicates the entrance of hepatocytes to the $S$ phase and may be due to exhaustion of the proliferative capability of liver cells. The results confirmed earlier data on the effects of PTU on the expression of PCNA and other cell cycle proteins in normal and regenerating rat liver [34]. Further, inhibition of the expression of PCNA by a high level of p53 has been noticed [35]. It is difficult to conclude on the mechanism(s) through which PTU resulted in an upregulation of p53 in the liver because p53 functions are tightly regulated at several biochemical processes [36].

The pronounced alteration in serum transaminase enzymes, impairment of hepatic antioxidant enzymes with elevated oxidants, and changes in mitochondrial respiratory parameters in adult rat liver by PTU [37-39], as well as altered expression of catalase and C/EBP- $\beta$ along with catalase promoter methylation in adult male rat liver by neonatal PTU treatment [4], are suggestive of impairment of normal hepatic physiology. Normal liver functions are a combined and coordinated reflection of metabolic activities of different cell types [40]. Therefore, the marked changes noticed in the expression of genes by PTU in the present work as well as in earlier work [4, 37-39] are a pooled gross reflection of changes in the expression of genes of different types of liver cells which finally epitomizes overall liver physiology. Further studies on different hepatic cell types will improve our understanding regarding the mechanism of PTU action.

In conclusion, the results of the present study demonstrate that neonatal exposure to PTU affects hepatic physiology in adulthood by epigenetic alterations in the expression of several proteins involved in DNA methylation, genome stabilization, and cell proliferation.

\section{Acknowledgements}

S.K.B. is thankful to CSIR, Government of India, for providing a fellowship (Ref. No. CSIR/JRF/09/173 (0128)/2010-EMR-1). G.B.N.C. thanks UGC, New Delhi, for the award of Emeritus Fellowship. The authors also thank the DST, (DST-PURSE support) and the DBT, Government of India, New Delhi, for financial support.

\section{Disclosure Statement}

The authors declare no conflict of interest.

References

1 Vitug AC, Goldman JM: Hepatotoxicity from antithyroid drugs. Horm Res 1985;21:229234.

$\checkmark 2$ Rivkees SA, Szarfman A: Dissimilar hepatotoxicity profile of propylthiouracil and methimazole in children. J Clin Endocrinol Metab 2010;95:3260-3267.

-3 Santana-Farre R, Mirecki-Garrido M, Bocos C, Henriquez-Hemandez LA, Kahlon N, Herrera E, Norstedt G, Parini P, Flores-Morales A, Fernandez-Perez L: Influence of neonatal hypothyroidism on hepatic gene expression and lipid metabolism in adulthood. PLoS One 2012; 7:e37386.

4 Bunker SK, Dandapat J, Sahoo SK, Roy A Chainy GBN: Neonatal persistent exposure to 6-propyl-thiouracil, a thyroid disrupting chemical, differentially modulates expression of hepatic catalase and C/EBP- $\beta$ in adult rats. J Biochem Mol Toxicol 2016;30:80-90.

5 Feil R, Fraga MF: Epigenetics and environment: emerging pattern and implications. Nat Rev Genet 2012;13:97-109. 
6 Goll MG, Bestor TH: Eukaryotic methyl cytosine methyltransferases. Ann Rev Biochem 2005;74:481-514.

7 Defossez PA, Stancheva I: Biological functions of methyl-CpG binding proteins. Prog Mol Biol Transl Sci 2011;101:377-398.

8 Hendrich B, Bird A: Identification and characterization of a family of mammalian methyl-CpG binding proteins. Mol Cell Biol 1998; 18:6538-6547.

9 Ballestar E, Wolffe, AP: Methyl-CpG-binding proteins: targeting specific gene repression. Eur J Biochem 2001;268:1-6.

10 Hollander MC, Fornace AJ Jr: Genomic instability, centrosome amplification, cell cycle checkpoints and Gadd45a. Oncogene 2002 21:6228-6233.

11 Vousden KH, Ryan KM: p53 and metabolism. Nat Rev Cancer 2009;9:691-700.

$\checkmark 12$ Livak KJ, Schmittgen TD: Analysis of relative gene expression data using real-time quantitative PCR and the $2^{-\Delta \Delta C}$ T method. Methods 2001;25:402-408.

13 Perandones CE, Illera VA, Peckham D, Stunz LL, Ashman RF: Regulation of apoptosis in vitro in mature murine spleen T cells. J Immunol 1993; 15:3521-3529.

14 Singh NP, McCoy MT, Tice RR, Schneider EL: A simple technique for quantification of low level of DNA damage in individual cells. Exp Cell Res 1988;175:184-191.

15 Bradford MM: A rapid and sensitive method for the quantification of microgram quantities of protein utilizing the principle of protein-dye binding. Anal Biochem 1976;72: 248-254.

$\$ 16$ Fuks F, Burgers WA, Brehm A, Hughes-Davies L, Kouzarides T: DNA methyltransferase Dnmt 1 associates with histone deacetylase activity. Nat Genet 2000;24:88-91.

17 Grøntved L, Waterfall JJ, Kim DW, Baek S, Sung MH, Zhao L, Park JW, Nielsen R, Walker RL, Zhu YJ, Meltzer PS, Hager GL, Cheng SY: Transcriptional activation by the thyroid hormone receptor through ligand-dependent receptor recruitment and chromatin remodeling. Nat Commun 2015;6:7048.

-18 Okano M, Bell DW, Haber DA, Li E: DNA methyltransferases Dnmt3a and Dnmt3b are essential for de novo methylation and mammalian development. Cell 1999;99:247-257.

19 Chen CC, Wang K-Y, Shen C-KJ: The mammalian de novo DNA methyltransferases DNMT3a and DNMT3b are also DNA 5-hydroxycytosine dehydroxymethylases. J Biol Chem 2012;287:33116-33121.

20 Wade PA: Methyl CpG- binding proteins and transcriptional repression. Bioessays 2001;23: 1131-1137.

21 Sui L, Li BM: Effects of perinatal hypothyroidism on regulation of reelin and brain-derived neurotrophic factor gene expression in rat hippocampus: role of DNA methylation and histone acetylation. Steroids 2010;75:988997.

22 Kreutzer DA, Essigmann JM: Oxidized, deaminated cytosines are a source of $\mathrm{C} \rightarrow \mathrm{T}$ transitions in vivo. Proc Natl Acad Sci USA 1998; 95:3578-3582.

23 Lee DH, O’Connor TR, Pfeifer GP: Oxidative DNA damage induced by copper and hydrogen peroxide promotes $\rightarrow$ TT tandem mutations at methylated $\mathrm{CpG}$ dinucleotides in nucleotide excision repair-deficient cells. Nucleic Acids Res 2002;30:3566-3573.

24 Ezeonwuka CD, Rastegar M: MeCP2 related diseases and animal models. Diseases 2014;2: 45-70.

25 Kimura H, Shiota K: Methyl-CpG-binding protein, $\mathrm{MeCP} 2$, is a target molecule for maintenance of DNA methyltransferase, Dnmt1. J Biol Chem 2003;278:4806-4812.

26 Hapon MB, Varas SM, Jahn GA, Gimenez MS: Effects of hypothyroidism on mammary and liver lipid metabolism in virgin and late pregnant rats. J Lipid Res 2005;46:1320-1330.

27 Kyle SM, Saha PK, Brown HM, Chan LC, Justice MJ: MeCP2 co-ordinates liver lipid metabolism with the NCoR1/HDAC3 corepressor complex. Hum Mol Genet 2016;25:30293021.

28 Esfandiari F, Green R, Cotterman RF, Pogribny IP, James SJ, Miller JW: Methyl deficiency causes reduction of the methyl-CpG-binding protein, $\mathrm{MeCP} 2$, in rat liver. Carcinogenesis 2003;24:1935-1940.

29 Jin S, Tong T, Fan W, Antinore MJ, Zhu X, Mazzacurati L, Li X, Petrik KL, Rajasekaran B,
Wu M, Zhan Q: Gadd45-induced cell cycle G2-M arrest associates with altered subcellular distribution of cyclin B1 and is independent of 38 kinase activity. Oncogene 2002:21: 8696-8704.

30 Lin R, Wang Y: Dysregulated transcriptional and post-translational control of DNA methyltransferases in cancer. Cell Biosci 2014;19: 46.

31 Liu D, Xu Y: p53, oxidative stress and aging. Antioxid Redox Signal 2011;15:1669-1678.

32 Vairapandi M, Balliet AG, Hoffman B, Liebermann DA: Gadd45b and Gadd45g are cdc2/cyclinB1 kinase inhibitors with a role in $\mathrm{S}$ and G2/M cell cycle checkpoints induced by genotoxic stress. J Cell Physiol 2002;192:327338.

33 Liebermann DA, Hoffman B: Gadd45 in stress signaling. J Mol Signal 2008;3:15.

-34 Alisi A, Demori I, Spagnuolo S, Pierantozzi E, Fugassa E, Leoni S: Thyroid status affects rat liver regeneration after partial hepatectomy by regulating cell cycle and apoptosis. Cell Physiol Biochem 2005;15:69-76

-35 Paunesku T, Mittal S, Protic M, Oryhon J, Korolev SC, Joachimiak A, Woloschak GE: Proliferating cell nuclear antigen (PCNA): ringmaster of the genome. Int J Radiat Biol 2001 77:1007-1021.

36 Kruse J, Gu W: Modes of p53 regulation. Cell 2009;137:609-622.

37 Subudhi U, Chainy GBN: Expression of hepatic antioxidant genes in L-thyroxine-induced hyperthyroid rats: regulation by vitamin $\mathrm{E}$ and curcumin. Chem Biol Interact 2010;183:304-316.

- 38 Subudhi U, Chainy GBN: Curcumin and vitamin E modulate hepatic antioxidant gene expression in PTU-induced hypothyroid rats. Mol Biol Rep 2012;39:9849-9861.

39 Mukherjee S, Samanta L, Roy A, Bhanja S, Chainy GBN: Supplementation of $\mathrm{T}_{3}$ recovers hypothyroid rat liver cells from oxidatively damaged inner mitochondrial membrane leading to apoptosis. Biomed Res Int 2014; 2014:590897.

40 Kmiec Z: Cooperation of liver cells in health and disease. Adv Anat Embryol Cell Biol 2001;161:1-151.
Neonatal Exposure to PTU Affects

Hepatic Physiology in Adulthood 